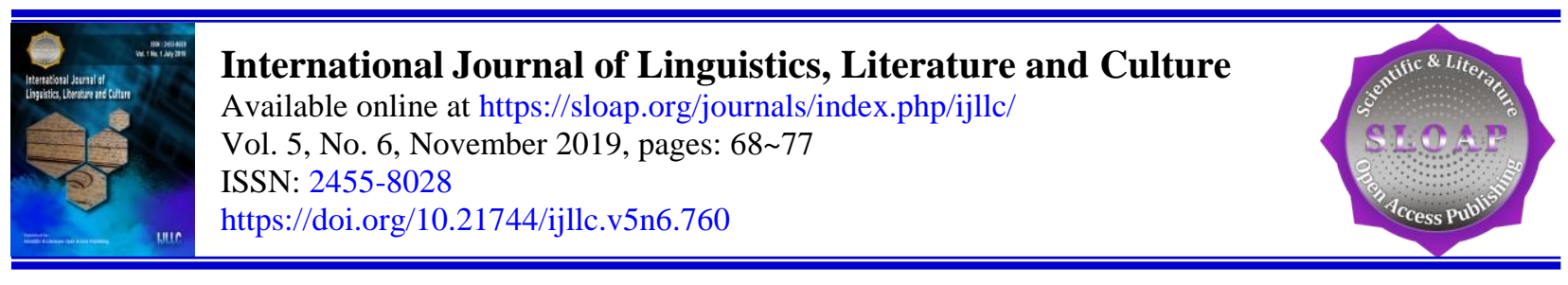

\title{
Stylistic Analysis of Charles Lamb's Essay Dream Children-Reverie
}

\author{
Kainat Ali ${ }^{\text {a }}$ \\ Shadab Fatima ${ }^{b}$ \\ Tarique $^{c}$ \\ Rashid Chandio $^{d}$
}

Article history:

Received: 18 May 2019

Accepted: 30 September 2019

Published: 26 October 2019

\section{Keywords:}

charles lamb;

literary;

style;

stylistic analysis;

themes;

\begin{abstract}
The study has been designed to analyze a literary piece that is "Dream Children Reverie" written by Charles Lamb via stylistics. The stylistic study deals with linguistic, graphological, phonological, grammatical, syntactical and structural aspects of the essay. In the study, the text has been explicated via stylistics analysis of the literary devices and style in which the text has been composed of. The study excavates various literary devices from the essay like symbolism, imagery, humor, and pathos that provides ancillary support to the overall meaning and impact of the essay. The present paper is a comprehensive study of literary text via a linguistic perspective. In addition, the study is also useful to find out themes in the essay Dream Children Reverie and it ensures to depict the self-portraying nature of the composition.
\end{abstract}

2455-8028 ${ }^{\circ}$ Copyright 2019. The Author. This is an open-access article under the CC BY-SA license (https://creativecommons.org/licenses/by-sa/4.0/) All rights reserved.

\section{Author correspondence:}

Rashid Chandio,

Department of English, Shaheed Benazir Bhutto University, Shaheed Benazirabad, Pakistan.

Email address: rashidchandio92@gmail.com

\section{Introduction}

Style is taken from the Latin word "elocution" particularly it stands for style and in Greek it means lexis. It has not a constant meaning but it is varying inside and outside the literature. More specifically in literature, it is dealing with the person's personality and it is nothing but voice or sound of the writer which is reflecting throughout the essay in the form of words, tone of ideas, the structure of a sentence, and writer's mindset. It reflects an idea that what the intentions of the composer are. This essay is in the "Essays of Elia". He has written this essay in the memory of his aunt, brother, grandmother, lover and sister. Basically, it stands for reverie which means an imaginative thought absentminded dreaming while awake (Lutfi Hussein \& Ali Dawood, 2018; Chandio et al., 2019; Rahman, 2018). In which the writer is communicating in words his feelings, emotions, and notions about losses and he is regretting. There is a description

a Shaheed Benazir Bhutto University, Sindh, Pakistan

${ }^{\mathrm{b}}$ Shaheed Benazir Bhutto University, Sindh, Pakistan

${ }^{c}$ University Tun Hussein Onn Malaysia, Parit Raja, Malaysia

${ }^{\mathrm{d}}$ Shaheed Benazir Bhutto University, Sindh, Pakistan 
of a particular place, narrator's personal relationships with his grandmother, brother, children and his beloved. These all events are not existing in his preset but they remained part of past time. Fundamentally it is based on the dream because the narrator is single and alone in his real-life but the whole essay is reflecting his personal desires and interests. The essay reflects the nobility of the writer, his simple and effective thoughts. One of the features of his essay is that it's full of juxtaposition. He used to change the names of his personal relations in his essays in order to hide his identity but the literature is highlighting his inner deep feelings which he has portrayed in the form of words (Lamb, 1892; Courtney, 1984).

Charles Lamb was born on $10^{\text {th }}$ February in 1775 in London England and died on $27^{\text {th }}$ of December in 1834 . His greatest achievements in the fields of literature include "Essays of Elia". He was a close contemporary of both Samuel Tailor Coleridge and Leigh Hunt.

The impact of the Romantic well-known essay is less shown but nevertheless important because Pater's essays in The Guardian newspaper and various journals prosperously adopt the light tone and personalized voice of an essay by Charles Lamb. In an essay on Charles Lamb, Pater appreciates the writing style of Lamb and defines it:

(There are) glimpses, suggestions, delightful half-apprehensions, profound thoughts of old philosophers, hits of the inner-most reasoning things, the full knowledge of which is held in reserve; all the varied stuff that is, of which genuine essays are made. ("Charles Lamb" 117)

He used to compose his essays under pseudonym Elia which had elevated his reputation and his essays are still remembered and included in the different courses related to Literature. His style of writing is more specifically personal but interesting in its touch. He belonged to a romantic age so the romanticism is found in his works. He possessed all traits of a romantic writer. There is an amalgamation of humor, pathos, imagination, diction and simple language in the essays. Sometimes the language is not so easy but it is an appealing one. Lamb's essays are playful and fanciful. Lamb has a great command of writing autobiographical forms (Lamb \& Lamb, 1903; Lamb Jr \& Lamb, 2019).

\section{Literature Review}

Charles Lamb is a shining star in the sky of English essays. He is called the prince among English essayists. His essays are the finest in English prose. He brought to prose the finest qualities of Romanticism. Lamb's readers appreciate him for his wisdom, for his humanity, for his genial humor, for his profound pathos, for his sweet temperament and for his style (Roy et al., 2016). As Edmund Blunden states about Lamb's essays "range from the vision of beautiful children that never were to be to the drollery consequent upon old George Dyer's tumbling into the New River's tenuous trickle, from nonsensical rebellion against Beethoven, Bath, Mozart to the contemplation of true and false imaginative paintings" (Charles Lamb and his contemporaries, 1967) "With him, as with Montaigne, the desire of self-portraiture is below all mere superficial tendencies, the real motive in 'writing at all, desire closely connected with intimacy, that modern subjectivity which may be called the Montaigne's element in literature. In his each and every essay, we feel the vein of his subjectivity" (Charles Lamb, 119-120) Samuel C. Chew observes "Like all the romantics he is self revelatory, but there is nothing in him of the 'egotistical -sublime. 'Experience had made him too clear-sighted to take any individual, least of all himself, too seriously. The admissions his own weaknesses, follies, and prejudices are so many humorous warnings to his readers." (A Literary History of England: The Nineteenth Century and After (17891939) (Bramberger, 2013; Bilstein \& Peskoller, 2012).

It is Lamb who joins all the fundamental components of paper writing in his papers with incredible creative greatness. Lamb stays extraordinary compared to other cherished writers of English writing not just for the respectability of his life and delicacy of heart yet additionally to deliver a group of writing one of a kind in esteem. To put it plainly, Lamb's expositions have been a perpetual wellspring of intrigue and joy to every one of the peruses of English writing (Bramberger, 2012; Qian, 2010).

The number of authors had written their different point of views regarding to various related topics. "Dream Children as an Essay" (cited in June 2009) and the name of author is Sibaprasad in which he has given a brief discussion about the summary of the essay. He explains that it is a subjective essay which is dealing with the lamb's own life as he has totally reflected himself. Deepawali Joshi contract faculty (English)M.B.P.G College, Halwani, Naintal (UK) as wrote a research paper under the title "A Critical Study Of Content, Language And Style in the essays of Charles Lamb and Robert Lynd: the a special reference of Dream children-reverie and A disappointed man" which was (cited in May 2015). In which she has kept her focus on the language, style, and content. As these factors are supposed to give literary form or say to two particular essays. She is enabling the readers to learn the specific techniques of how to contrast two writers' works with the help of virtual dimensions of vision, original text. A Freudian View of Charles

Ali, K., Fatima, S., Tarique, T., \& Chandio, R. (2019). Stylistic analysis of charles lamb's essay dream childrenreverie. International Journal of Linguistics, Literature and Culture, 5(6), 68-77. https://doi.org/10.21744/ijllc.v5n6.760 
Lamb's "Dream children-reverie "was (cited in 2014) and the author is Dr. HC Puja Chakraborty. In this the author has discussed the essay under the literary theory (psychoanalytical theory).

\section{Materials and Methods}

The present study is qualitative in nature in which textual analysis and close study have been used as tools for interpretation of the data. The study employs stylistics as a theoretical framework via which findings have been highlighted.

\section{Results and Discussions}

Charles Lamb's writing style reflects his self-revelation as Samuel C. Chew observes, "Like all the romantics he is self -revelatory, but there is nothing in him of the 'egotistical -sublime. 'Experience had made him too clear-sighted to take any individual, least of all himself, too seriously. The admissions of his own weaknesses, follies, and prejudices are so many humorous warnings to his readers" (A Literary History of England: The Nineteenth Century and After (1789-1939).

In "Dream Children - A Reverie" Lamb has described the following aspects:

\section{Psychology of children:}

Lamb has beautifully portrayed the psychology of children that they are always in unease position, cannot control their concentration on a single thing or the things that they are directed to do or follow. They immediately change their direction when someone is looking over them and it felt that they are not comfortable. They are restless in a way that they cannot sit on a chair all the time. He has also mentioned that children are more attractive and have complete attention towards food which is tasty and desirable. When there is a meal for them, they are supposed to lose their attention towards surroundings and only think about to eat the food. This is nothing but an innocent nature of children. They can easily be won by little things which make them satisfied and they feel that their desires are fulfilled. That's why in the literary theories, the psychoanalytical theory is applied but our concern is with stylistic analysis.

This can be observed from the following lines:

“...here Alice's little right foot played an involuntary movement, till, upon my looking grave, it desisted"

"Here John slyly deposited back upon the plate a bunch of grapes, which, not unobserved by Alice, he had meditated dividing with her, and both seemed unwilling to relinquish them for the present as irrelevant" (Essays of Elia, 1823)

\section{Memories:}

An essay is based on the events or records that took place in the past time. He has designed his personal experience in it that he is badly missing his grandmother, brother John L, house fields, his beloved Ann. It has an imaginary touch but it has also the essence of feelings, emotions, and feelings of loneliness that give it perfect organic plot. Lamb is missing the days which he has devoted to his grandmother. His essay is showing his attitude and behavior towards his personal experience which he used to memorize (Lamb, 1852; Lucas \& Lamb, 1905).

\section{Solitariness:}

In starting lines, he has provided commentary and a detailed account of ant imagery world in which there are children, brother, grandmother, home fields it is nothing but a dream which is far away from reality but in end, he is saying that there is bachelor seat. It means in real-world he has no children, no wife, no brother and no great grandmother but indeed he is alone in his life and he is missing them in his loneliness.

"We are not of Alice, nor of thee, nor are we children at all. The children of Alice called Bertram father. We are nothing; less than nothing, and dreams. We are only what might have been, and must wait upon the tedious shores of Lethe millions of ages before we have existence and a name"

"....and immediately waking, I found myself quietly seated in my bachelor arm-chair, where I had fallen asleep" (Essays of Elia, 1823) 
This section will provide stylistic analysis of the essay "Dream children-reverie" of Charles Lamb. By examining lexical features, syntactical structure, grammatical features, graphology, Phonological level, diction, literary devices, description in detail and cohesion in the sentence (Aaron \& Aaron, 1991; Lamb, 1897).

\section{Lexical level}

In this lexical level the lexicon or constitutes are being separated, such as the grammatical unit nouns, pronouns, verbs, adverbs, prepositions, conjunction, and interjections in order to categorize them into different lexical categories.

Table 1

Lexical level

\begin{tabular}{|c|c|c|c|}
\hline Nouns & Pronouns & Verbs & Adjectives \\
\hline Children & They & Love & Great \\
\hline Stories & their & Listen & Bigger \\
\hline Elders & it & Were & Cruel \\
\hline Imagination & this & Stretch & Red \\
\hline Conception & that & Hear & Rich \\
\hline Uncle & my & Was & Foolish \\
\hline Grandma & me & $\mathrm{Had}$ & Dear \\
\hline Field & whom & Lived & Good \\
\hline House & who & Saw & Graceful \\
\hline Norfolk & her & Become & Newer \\
\hline Papa & his & Is & Old \\
\hline Ballad & $\mathrm{i}$ & Seen & Best \\
\hline Wood & she & Pulled & Courageous \\
\hline Chimney & myself & Set & Tall \\
\hline Hall & them & Stead & Twelve \\
\hline Robin & he & Called & Innocent \\
\hline Person & how & Went & Huge \\
\hline \multirow[t]{2}{*}{ Marble } & when & Say & Spacious \\
\hline & we & Beloved & Pleasure \\
\hline Invention & you & Respected & Silent \\
\hline Mistress & those & Said & Sweet \\
\hline Owner & & Committed & Much \\
\hline Country & & Preferred & Pretty \\
\hline \multirow[t]{2}{*}{ John } & & Living & Fair \\
\hline & & Purchased & Tedious \\
\hline Woman & & Kept & Certain \\
\hline Alice & & Came & Fashionable \\
\hline Hands & & Decay & Other \\
\hline Graceful & & Stripped & Some \\
\hline Dancer & & Carried & Away \\
\hline Disease & & Looked & Such \\
\hline Cancer & & Carry & Many \\
\hline Maid & & Stick & Lone \\
\hline Eyebrows & & Die & Frightened \\
\hline Caesars & & Attended & Oaken \\
\hline Emperors & & Show & Spacious \\
\hline Rome & & Spread & About \\
\hline Rooms & & Sleep & Only \\
\hline Panels & & Used & Modern \\
\hline Gardens & & Believed & Little \\
\hline Nectarines & & Gliding & All \\
\hline
\end{tabular}

Ali, K., Fatima, S., Tarique, T., \& Chandio, R. (2019). Stylistic analysis of charles lamb's essay dream childrenreverie. International Journal of Linguistics, Literature and Culture, 5(6), 68-77. 


\begin{tabular}{|c|c|c|}
\hline Peaches & Expanded & Involuntary \\
\hline Walls & Look & Vast \\
\hline Fruits & Gazing & Particular u \\
\hline Apples & Seem & \\
\hline Berries & Roaming & \\
\hline Grass & Gilding & \\
\hline Trees & Empty & \\
\hline Fish & Turned & \\
\hline Pond & Rubbed & \\
\hline Dace & Hanging & \\
\hline Oranges & Carved & \\
\hline Plate & Cross & \\
\hline King & Pluck & \\
\hline Corners & Stood & \\
\hline Man & Impressed & \\
\hline Boy & Found & \\
\hline Lame & Fallen & \\
\hline Life & Gone & \\
\hline Death & Seated & \\
\hline Soul & Explained & \\
\hline Eyes & Turning & \\
\hline Father & Mourning & \\
\hline Armchair & Crying & \\
\hline Bridget & Wished & \\
\hline James Elia & Knew & \\
\hline Whole & Haunted & \\
\hline Pain & Pent & \\
\hline Manner & Relinquish & \\
\hline Dignity & Get & \\
\hline Neighborhood & Darted & \\
\hline Poor & Smells & \\
\hline gilt & Forbidden & \\
\hline stoop & Mocked & \\
\hline gentry & Unobserved & \\
\hline right & Heightened & \\
\hline round & Like & \\
\hline testament & Receding & \\
\hline half & Awaking & \\
\hline \multicolumn{3}{|l|}{ holidays } \\
\hline \multicolumn{3}{|l|}{ Somewhere } \\
\hline \multicolumn{3}{|l|}{ Tender } \\
\hline \multicolumn{3}{|l|}{ Midnight } \\
\hline Miles & & \\
\hline
\end{tabular}

Table 2

Adverbs

\begin{tabular}{l}
\hline Adverbs \\
\hline Generally \\
Lately \\
For \\
Especially immediately \\
Still \\
Though \\
\hline
\end{tabular}




\begin{tabular}{l}
\hline Quietly \\
Yet \\
Too \\
While \\
Nearly \\
Here \\
Never
\end{tabular}

Graphological level:

1. It is an essay of normal length.

2. It is rich in imaginary

3. There is capitalization.

4. One can visualize the punctuation.

5. There some spelling errors

For example commas, semicolon, full Stop, and inverted commas, etc.

Grammatical level: usage of punctuation, full stops, and commas, it means the writer is narrating his own life in order to please the readers by using the proper method of writing. There is no use of question marks or exclamation signs.

Phonological level:

Repetition of thoughts:

There is the repetition of the word for instance

Altogether is repeated for eight times, he repeats it when he is talking about attractive, pleasing and inspiring actions. He is doing it in order to display the real picture of children in front of the readers when they are going through it. The main purpose of the repetition of words is to emphasize the real picture of children.

"Then I went on to say, how good and how religious their great grandmother Field was."

"...because she had such a good and religious person"

".... because I was never half so good or religious as she"

This is repeated form three times

Another example is

"Then I told how good she was to all her grand-children"

“.... I told how, though their great-grandmother Field loved all her grand-children (Essays of Elia, 1823)

Diction:

He has used old-fashioned vocabulary but refined and tasteful appearance or behavior of style, which is giving it a polished touched.

1. 1.Esteemed (having an illustrious reputation, respected)

2. Desisted (it means to stop doing)

3. Plunk (poetic lexical it means to pick)

4. Mediated (thought) and relinquish (to give up)

Cohesion in sentences:

Ideas, thoughts, and notions are connected together and give us a proper meaning. Sentences are joined in order to give it a perfect shape. The sentences are arranged in order to make an essay more comprehend. The sentences are written in preset, past indefinite tenses and also in past participles. These techniques are enough to give it an organic touch.

Tone:

It is dealing with the language or more specific mode of converting ideas, notions, feelings, and emotions by using formal or informal statement but lamb is most famous for his informal and conversational statements.

Informal and conversational:

Charles lamb's essay starts or begins with the conversational and informal statement, which is direct or literary it's the aphoristic statement. He is not feeling hesitate in sharing his personal experience with us. It can be tasted from the text

Ali, K., Fatima, S., Tarique, T., \& Chandio, R. (2019). Stylistic analysis of charles lamb's essay dream childrenreverie. International Journal of Linguistics, Literature and Culture, 5(6), 68-77. https://doi.org/10.21744/ijllc.v5n6.760 
"Children love to listen to stories about their elders when they were children to stretch their imagination......" (Essays of Elia, 1823)

\section{Literary devices:}

Following are literary instruments in dream children-reverie in which symbolism, imagery, juxtaposition, humor and pathos are mentioned below:

\section{Symbolism:}

There is the usage of symbols in the essay in the following manner

"All its old ornaments stripped" (Essays of Elia, 1823)

It indicates, hints or reflects the modern conditions of that particular society he says the children have moved to modern or fashionable areas though they have their own great grandmother's home. But the old tradition and civilization are not like that they should be.

"I found myself quietly seated in my bachelor arm-chair" (Essays of Elia, 1823)

It shows that he has no wife that is his better half and no children as he states bachelor's seat, and Symbolically it means he is alone in his life.

\section{Juxtaposition:}

When two different ideas are joined together or stated together is called juxtaposition. Busy idle is a juxtaposition in this essay. Lamb is in a busy mood because he is recalling the events that took place in the past time, thoroughly he is not free but continuously he has diversions. The rest of the events are not fruitful because these are chapters of past or he is trying to make himself busy.

"I had more pleasure in these busy-idle diversions than in all the sweet flavors of peaches, nectarines, oranges and such-like common baits of children" (Essays of Elia, 1823)

Imagery:

An imaginative picture is presented by lamb such as children, brother, dream, seat, grandmother, Ann, peaches, oranges, chair, fields, apples, walls, eyebrows, etc.

\section{Humor and pathos:}

J.B Priestley asserts English humor at its deepest and tenderness seems in him (Lamb) incarnate. He did not merely create it, he lived in it. His humor is not an idle thing, but the flower plucked from a most dangerous nettle." (English Humor, 1929)

In real life, Lamb has no children, wife but in the dream that's fantasy, he is married to Alice and has children. While he had a broken heart due to his beloved as he was not a success in the case of love. He made a complete circle of life in which both light and dark shades are painted.

Walter Pater maintains in "Appreciations: With an Essay on Style"

"what sudden, unexpected touches of pathos in him! bearing witness how the sorrow of humanity, the Welt-schmerz, the constant aching of its wounds, is ever-present with him: but what a gift also for the enjoyment of life in its subtitles, of enjoyment actually refined by the need of some thoughtful economies and making the most of things! Little arts of happiness he is ready to teach others." (Charles Lamb, 112)

From the beginning, it is seeming that the story is not imagination but in end, we come to know that he has planned it and one can feel sympathy for an author that is called pathos (feelings of sorrows for the misfortune of Charles Lamb.

\section{Description In detail:}

Dream children-reverie is not too much long essay but it's precise one, in this lamb has applied detailed descriptive events in which there is a record of John L who is presented as bother of Lamb. There is an account of the great grandmother field's house. These all different events are included in the story as follows;

".... I never could be tired with roaming about that huge mansion, with its vast empty rooms, with their worn-out hangings, fluttering tapestry, and carved oaken panels, with the guiding almost rubbed out..."

".....and how the nectarines and peaches hung upon the walls...... among the old melancholy-looking yew trees, or the firs, and picking up the red berries, and the fir apples...... with the oranges and limes in that grateful warmth....." (Essays of Elia, 1823) 


\section{Conclusion}

The essay dream children-reverie is written in autobiographical form or style. Charles Lamb has an informal stylistic approach but he has made a successful attempt in order to compose an interesting writing style that is concerned with his own life. He has composed praiseworthy work which is full of imagination, symbolism, and simple language and related to his experiences. His unique style is enough to give it an elevated position in the history of English literature. $\mathrm{He}$ is rightly called the prince of English essays. Lamb's style is the statement of his identity. His style is matchless. His expositions have the appeal of verse. Conversational simplicity, epigrammatic profundity, passionate adaptability, reminiscent allusiveness all check the expositions of Elia. Sheep's style is normal and unique. He is astoundingly affected by the seventeenth-century journalists like Brown, Burton, and Fuller. He regularly utilized outdated Latinized words. Allusiveness is a checked component of his style. He frequently cites from the old journalists to express his emotions. Lamb makes visit utilization of incongruity and quip. J. C. Poway's composes,' Elia's style is the main thing in English exposition that can be called completely great.'

\section{Conflict of interest statement}

It is declared by authors that there is not any conflict of competing intend in the study but equal contribution has been made to accomplish this paper.

\section{Statement of authorship}

All the authors take sole responsibility for the design and enterprise of this study and with an equal agreement, this article is approved by authors.

\section{Acknowledgments}

The authors would like to acknowledge the editor of IJLLC for accepting this article to be published in the journal.

Ali, K., Fatima, S., Tarique, T., \& Chandio, R. (2019). Stylistic analysis of charles lamb's essay dream childrenreverie. International Journal of Linguistics, Literature and Culture, 5(6), 68-77. 


\section{References}

Aaron, J., \& Aaron. (1991). A double singleness: Gender and the writings of Charles and Mary Lamb (p. 137). Oxford: Clarendon.

Bilstein, J., \& Peskoller, H. (2012). Lesend die Welt erfahren. Erfahrung-Erfahrungen, 159.

Bramberger, A. (2012). Poetry for Children: Reverie and the Demand for the Teacher's Responsibility. Journal of Aesthetic Education, 46(2), 14-24.

Bramberger, A. (2013). Lyrik für Kinder. Rêverie und die Verantwortung Lehrender. In Erfahrung-Erfahrungen (pp. 181-193). Springer VS, Wiesbaden.

Chandio, R., Fatima, S., Tarique, T., \& Soomro, S. (2019). The stylistics analysis of the poem "raqeeb se, to the rival" by Faiz Ahmed Faiz. International Journal of Linguistics, Literature and Culture, 5(6), 36-47. https://doi.org/10.21744/ijllc.v5n6.756

Courtney, W. F. (1984). Young Charles Lamb 1775-1802. Springer.

Lamb Jr, C., \& Lamb, M. A. (2019). The Letters of Charles and Mary Anne Lamb: 1809-1817. Cornell University Press.

Lamb, C. (1852). The Works of Charles Lamb. E. Moxon.

Lamb, C. (1892). The Dramatic Essays of Charles Lamb. Dodd, Mead.

Lamb, C. (1897). The life, letters, and writings of Charles Lamb (Vol. 1). Gibbings.

Lamb, C., \& Lamb, M. (1903). The Works of Charles and Mary Lamb (Vol. 2). Methuen \& co..

Lucas, E. V., \& Lamb, J. (1905). The Life of Charles Lamb (Vol. 2). Methuen \& Company.

Lutfi Hussein, A., \& Ali Dawood, Z. (2018). Salient socio-stylistic traits of English and Arabic junior songs. International Journal of Linguistics, Literature and Culture, 4(4), 86-102. https://doi.org/10.21744/ijllc.v4n4.270

Qian, J. (2010). Learning and Life: A Discussion Based on Aesthetic Judgments.

Rahman, B. (2018). The stylistics of text: wasiat renungan masa pengalaman baru. International Journal of Social Sciences and Humanities, 2(3), 149-155. https://doi.org/10.29332/ijssh.v2n3.225

Roy, K., Das, R. N., Ambure, P., \& Aher, R. B. (2016). Be aware of error measures. Further studies on validation of predictive QSAR models. Chemometrics and Intelligent Laboratory Systems, 152, 18-33. 


\section{Biography of Authors}

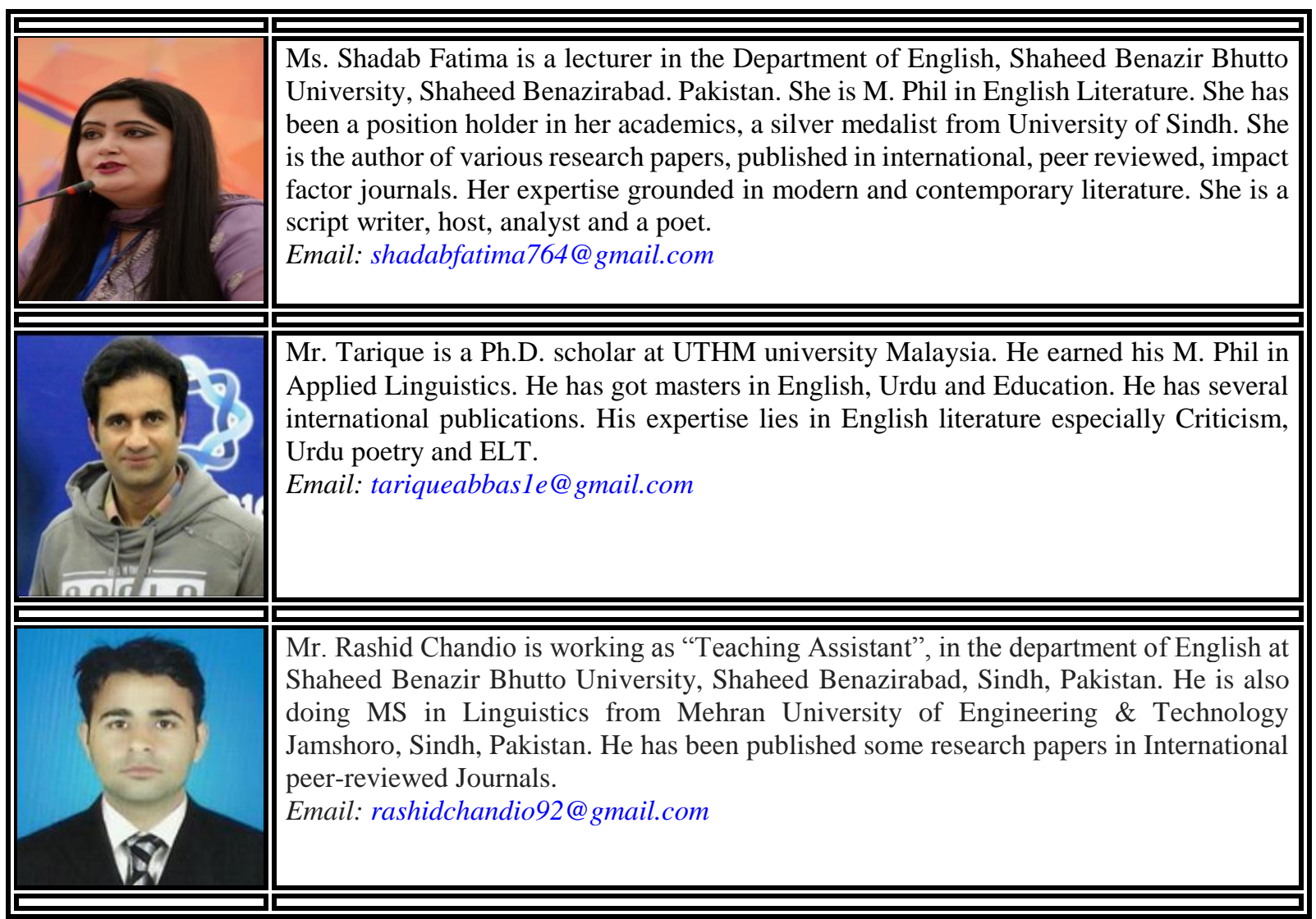

Ali, K., Fatima, S., Tarique, T., \& Chandio, R. (2019). Stylistic analysis of charles lamb's essay dream childrenreverie. International Journal of Linguistics, Literature and Culture, 5(6), 68-77. https://doi.org/10.21744/ijllc.v5n6.760 